\title{
RADIOCARBON CHRONOLOGY AND MAGNETIC SUSCEPTIBILITY VARIATION IN KUMAON LAKE SEDIMENTS
}

\author{
SHEELA KUSUMGAR, D P AGRAWAL \\ and \\ PRABHAKAR SHARMA \\ Physical Research Laboratory, Ahmedabad 380 009, India
}

\begin{abstract}
This study was carried out to determine time controls of erosion and sedimentation in the catchment area and lakes of the Naini Tal district in the Kumaon Himalayas. We present here our preliminary data from five lakes, Beon Tal, Garud Tal, Sukha Tal, Bhim Tal and Kamal Tal (Naukuchia Tal). A number of ${ }^{14} \mathrm{C}$ dates are now available to estimate the sedimentation rate of the five lakes and magnetic susceptibility $\left(\varkappa_{L} ; x_{f d}\right)$ variation to determine the signature of sediment source. High $x_{\mathrm{fd}}$ values indicate a higher proportion of soil component generally characterized by a slower rate of deposition, and low $\varkappa_{\mathrm{fd}}$ values with a higher rate of sedimentation indicate rock-debris-derived sediment. $\mathrm{A}{ }^{14} \mathrm{C}$ chronology enables us to estimate the mean sedimentation rate whereas rock magnetic properties help us to characterize the type of source responsible for sedimentation.
\end{abstract}

\section{INTRODUCTION}

A multidisciplinary study involving ${ }^{14} \mathrm{C}$ and ${ }^{210} \mathrm{~Pb}$ dating rock magnetic properties and palynology was undertaken in the Kumaon Himalayan lakes by Agrawal et al (1986) and Sharma et al (1988). The area of study $\left(29^{\circ} 18^{\prime}-\right.$ $29^{\circ} 22^{\prime} \mathrm{N}, 79^{\circ} 31^{\prime}-79^{\circ} 36^{\prime} \mathrm{E}$ ) (Fig 1) comprises the Naini Tal district lakes in the Kumaon Himalayas in the northern state of Uttar Pradesh, India. The region lies between the Himalayan range on the north and the Ganga plains on the south. Geologically, the lakes occurring between the altitude range of ca $1400 \mathrm{~m}$ (Bhim Tal-Sat Tal, Naukuchia Tal, etc) to $1935 \mathrm{~m}$ (Naini Tal) fall in the lesser Himalayan zone. The outer and lesser Himalayan zones are separated by the Main Boundary Thrust (MBT). According to Valdiya (1983) and Valdiya et al (1984), the MBT zone is tectonically active and the underthrusting of the Indian Plate under the Asian Plate is still taking place along this boundary.

Figure 1 gives a schematic map of the lakes, the main one being the Sat Tal complex comprising seven lakes (we studied Sukha Tal, Garud Tal and Beon Tal) Bhim Tal and Kamal Tal, a part of Naukuchia Tal, which gets dried up seasonally. We made trenches or drilled with hand auger in the seasonally dry parts of the lakes and obtained undisturbed layer-by-layer sediments for the study.

We discuss here sedimentation rates of these lakes based on ${ }^{14} \mathrm{C}$ and ${ }^{210} \mathrm{~Pb}$ dating of sediments in the lake beds. Coupled with rock magnetic properties of sediments, it enables us to understand the changes in erosion/ sedimentation regime of these lake catchments. A detailed description of the geology/geomorphology as well as vegetation of the lake catchments has been given by Agrawal et al (1986) and Sharma et al (1988).

The applicability of rock magnetic properties to sediment sourcing is based on the fact that a soil-derived sediment generally shows enrichment of ferrimagnetic minerals resulting in enhancement of both low frequency susceptibility $\left(\varkappa_{\mathrm{L}}\right)$ as well as quadrature susceptibility $\left(\varkappa_{\mathrm{fd}}\right)$ (Thompson \& Oldfield, 1986), the enhancement depending on the degree of soil development. 


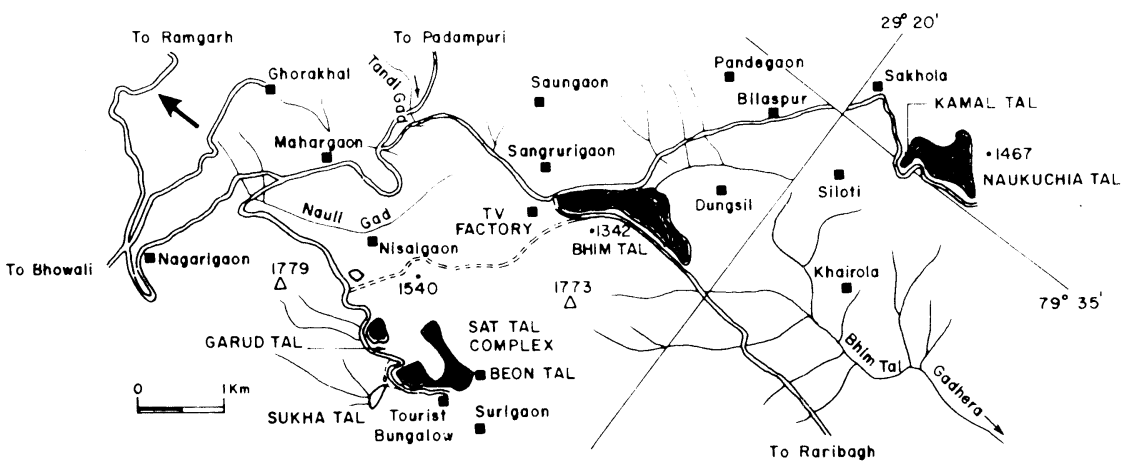

Fig 1. Location map of study area around Sat Tal - Bhim Tal - Naukuchia Tal (Kumaon Himalayas)

The magnetic susceptibility $\varkappa_{\mathrm{L}}$ of a given material is related to the concentration of ferrimagnetic minerals. The frequency-dependent component of magnetic susceptibility $\left(\varkappa_{\mathrm{fd}}\right)$ arises due to the presence of ultrafine ferrimagnetic grains around superparamagnetic/stable single domain boundary $(0.01-0.03 \mu \mathrm{m})$. The frequency-dependent property of magnetic susceptibility has been observed only for sediments which have either undergone pedogenesis, eg, soils, or have a soil-derived component and is characteristically absent in sediments in which a soil component is absent (eg, Thompson \& Oldfield, 1986).

Simultaneous measurement of $x_{\mathrm{L}}$ and $x_{\mathrm{fd}}$ enables us to distinguish clearly the active enhancement of concentration of ferrimagnetic minerals (resulting from conversion of antiferromagnetic iron oxide to ferrimagnetic forms during pedogenesis) from the passive enhancement caused by the leaching away of nonmagnetic components from the humus-rich horizon. Thus, a parallel increase of $x_{\mathrm{L}}$ as well as $x_{\mathrm{fd}}$ indicates enhancement of ferrimagnetic concentration of secondary origin caused by pedogenesis (pedogenetic component), whereas variations of $x_{\mathrm{L}}$ not associated with corresponding variation of $x_{\mathrm{fd}}$ indicate contribution of ferrimagnetic minerals of primary origin.

Some studies employing rock magnetic techniques for the identification of sediment sources in lake/river catchments have been reported. However, few well-controlled experiments have been undertaken to quantitatively establish the applicability of this technique (eg, Walling et al, 1979; Sharma et al, 1988).

We used ${ }^{210} \mathrm{~Pb}$ (for the top $20 \mathrm{~cm}$ ) as well as ${ }^{14} \mathrm{C}$ for the deeper sediments in the range of a few hundred to a few thousand years. For most of the lakes we had to estimate a mean sedimentation rate based on a single ${ }^{210} \mathrm{~Pb}$ or ${ }^{14} \mathrm{C}$ date, mainly due to the dearth of datable material, except for Kamal Tal, where we have several ${ }^{14} \mathrm{C}$ dates. As rock magnetic properties indicate changes in the sediment type in a profile, by combining the two techniques we have been able to meaningfully interpret the changes in the sedimentation rates in different lakes as explained below. The magnetic susceptibility $\left(x_{\mathrm{L}}\right)$ as well as its frequency-dependent component $\left(x_{\mathrm{fd}}\right)$ were measured in the laboratory by means of the Bartington AC susceptibility Bridge (Model MS1). 


\section{RESULTS}

Sat Tal complex

Beon Tal. A core of $1.8 \mathrm{~m}$ was obtained on which $\varkappa_{\mathrm{L}}$ and $\varkappa_{\mathrm{fd}}$ and ${ }^{14} \mathrm{C}$ were measured (Fig 2). The lithology was also texturally examined in the field. At ca $0.9 \mathrm{~m}$ and $1.4 \mathrm{~m}$ depths, soil mixed with crushed-rock debris was observed in the field, associated with low values of $\varkappa_{\mathrm{L}}$ as well as $\varkappa_{\mathrm{fd}}$. In the top $0.3 \mathrm{~m}$, dark-brown to black forest soil was observed, along with high values of $\varkappa_{\mathrm{L}}$ and $x_{\mathrm{fd}}$. There is a ${ }^{14} \mathrm{C}$ date of $890 \pm 90(\mathrm{PRL}-1106)$ at $1.75 \mathrm{~m}$ which indicates an average sedimentation rate of $1.97 \mathrm{~mm} / \mathrm{yr}$.
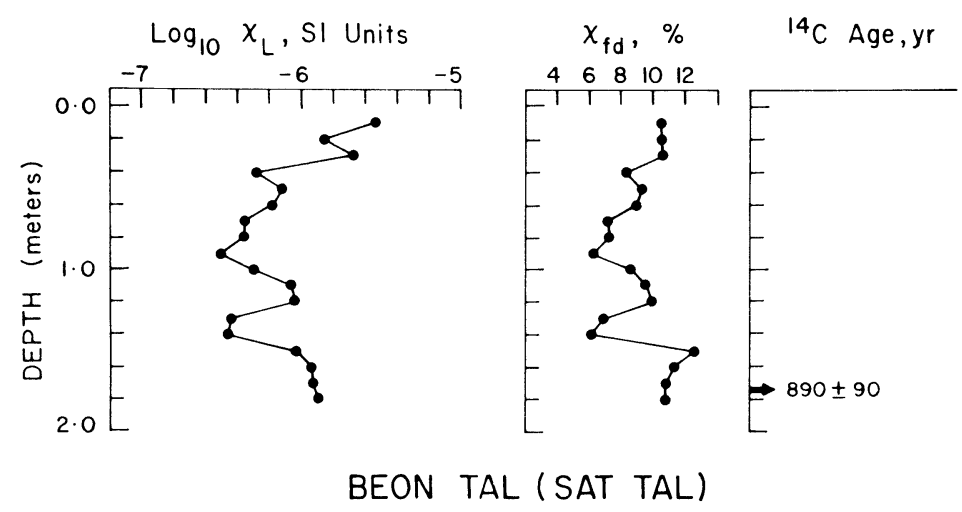

Fig 2. Mineral magnetic profiles of the Beon Tal sediment with a ${ }^{14} \mathrm{C}$ date

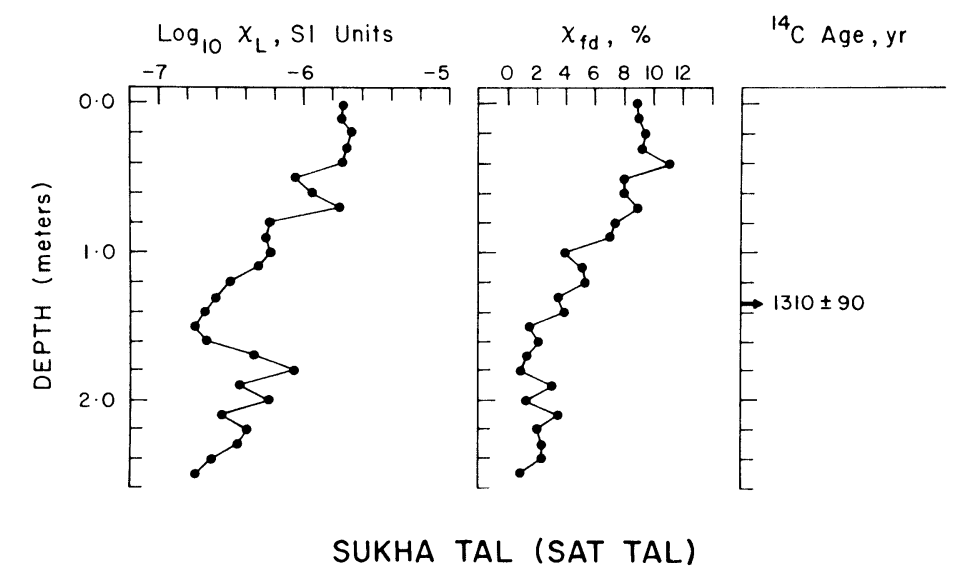

Fig 3. Mineral magnetic profiles of the Sukha Tal sediment with a ${ }^{14} \mathrm{C}$ date 
Sukha Tal. In this lake there is also parallelism between $\varkappa_{\mathrm{L}}$ and $\varkappa_{\mathrm{fd}}$ indicating a predominantly soil-derived component of sediment in the top $0.8 \mathrm{~m}$, a non-soil-derived component in the bottom $1.5 \mathrm{~m}$, with a mixture of the two in between (Fig 3). A ${ }^{4} \mathrm{C}$ date of $1310 \pm 90$ (PRL-1105) gives an average sedimentation rate of $1.05 \mathrm{~mm} / \mathrm{yr}$, which corresponds to the part of the profile predominantly contributed by the soil-derived material. Sedimentologically also there is a change at ca lm depth. Above this boundary the sediment is blackish and richer in soil-derived material and below, it is more clayey but deficient in organic carbon. As noted by Gupta and Khandelwal (1982), in the Sat Tal complex, $1400 \pm 100 \mathrm{BP}$ marks the beginning of agriculture and land-use as well as increasing Quercus and decreasing Pinus roxburghii. Elsewhere, Sharma et al (1988) have shown that modern oak forest soil shows a higher $\varkappa_{\mathrm{fd}}$ value compared to Pinus roxburghii forest soil.

Garud Tal. In the entire $1.8 \mathrm{~m}$ core, the $x_{\mathrm{L}}$ as well as $x_{\mathrm{fd}}$ values do not show any marked variation throughout the profile; $x_{\mathrm{fd}}$ being in the range of ca $8-10 \%$ suggestive of a predominantly soil-derived component (Fig 4). There is a ${ }^{14} \mathrm{C}$ date of $3000 \pm 100$ (PRL-1120) which gives an average sedimentation rate of $0.55 \mathrm{~mm} / \mathrm{yr}$, the lowest of the lakes studied in the Sat Tal complex. The sediment is very uniform, fine-grained and dark, organicrich with soil debris.

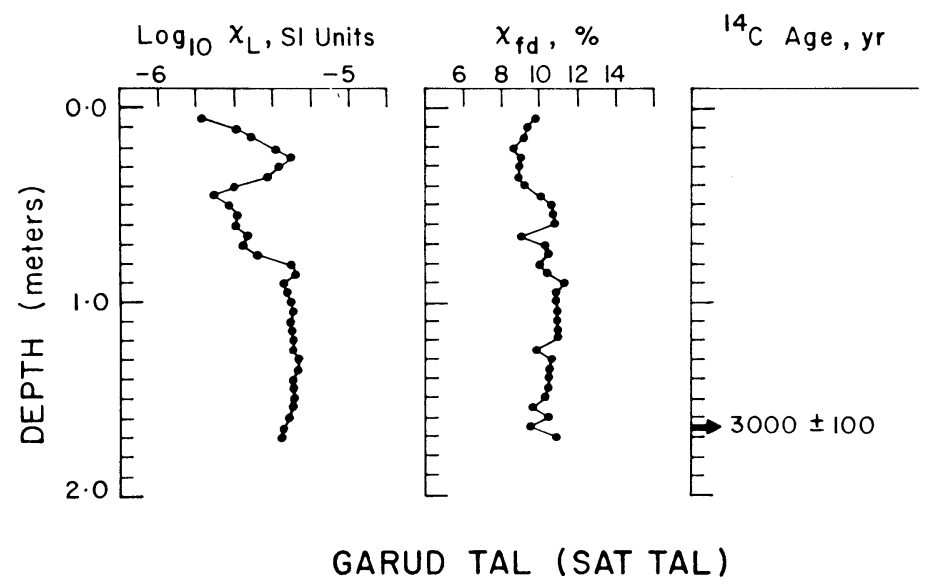

Fig 4. Mineral magnetic profiles of the Garud Tal sediment with a ${ }^{14} \mathrm{C}$ date

Bhim Tal. Two cores were collected from Bhim Tal lake - one from the inlet of the present lake, the other from a permanently silted up part on which a TV factory was constructed. Bhim Tal shows a consistently very low $(\approx 0 \%) x_{\mathrm{fd}}$ value. The $x_{\mathrm{L}}$ curve (Figs 5,6), however, shows marked fluctuations in both profiles indicating fluctuating concentration of ferrimagnetic minerals in the sediment input of a predominantly non-pedogenic type. The sediment shows a mixture of mud and sand with hardly any organic material. Thus we could not date the profile by ${ }^{14} \mathrm{C}$. However, the top $16 \mathrm{~cm}$ sediment has been dated by ${ }^{210} \mathrm{~Pb}$ to $24 \mathrm{BP}$ giving a sedimentation rate of $6.8 \mathrm{~mm} / \mathrm{yr}$.

Naukuchia Tal. We raised a 5.5m core from Kamal Tal which is a seasonally dry part of the Naukuchia Tal. The Kamal Tal profile is dominated 


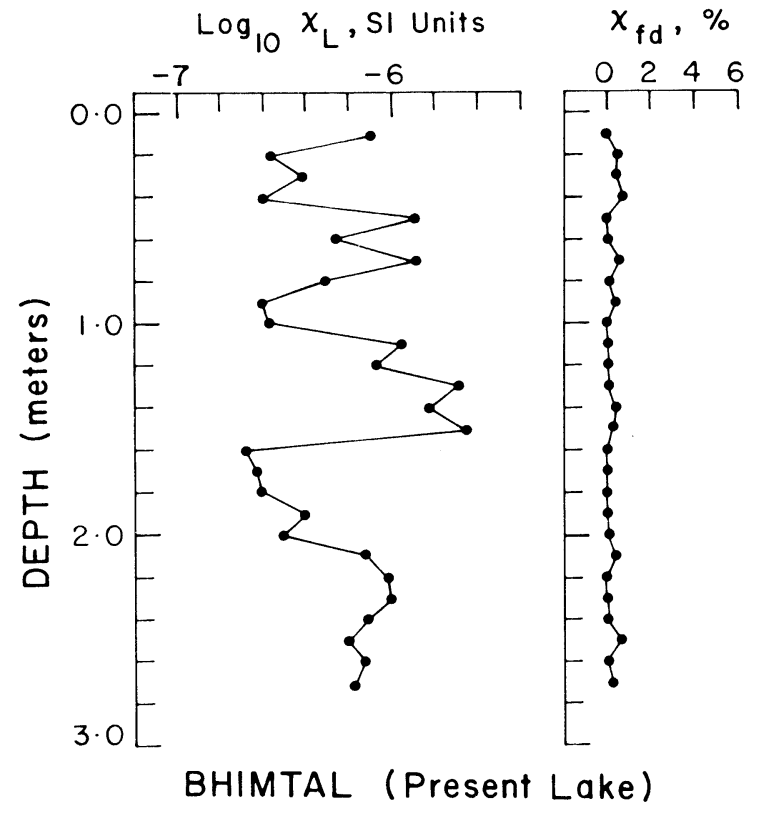

Fig 5. Mineral magnetic profiles of the Bhim Tal (present lake)

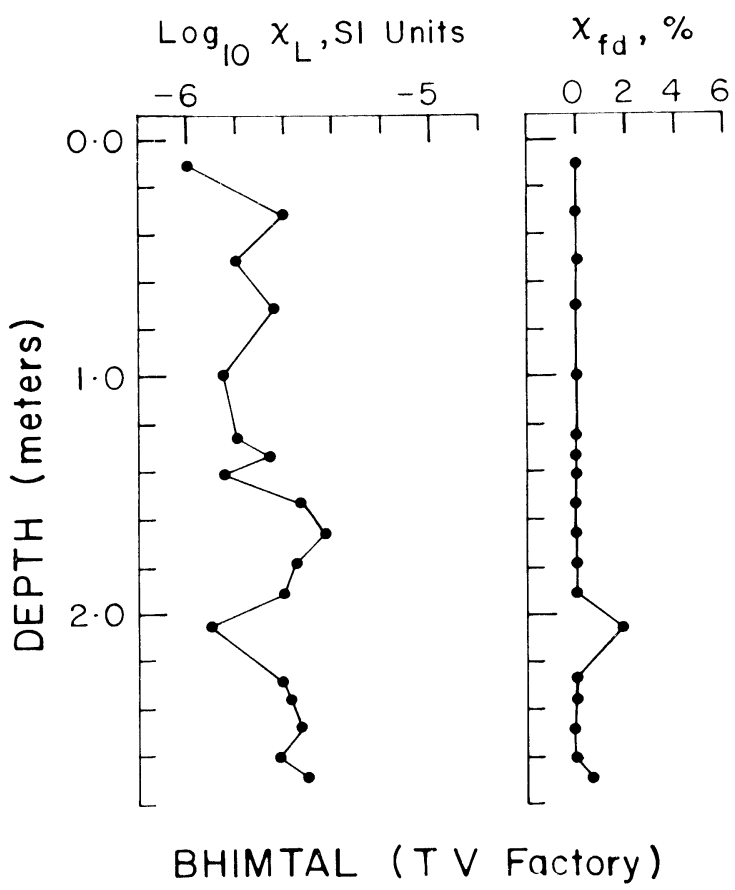

Fig 6. Mineral magnetic profiles of the Bhim Tal (TV factory) 


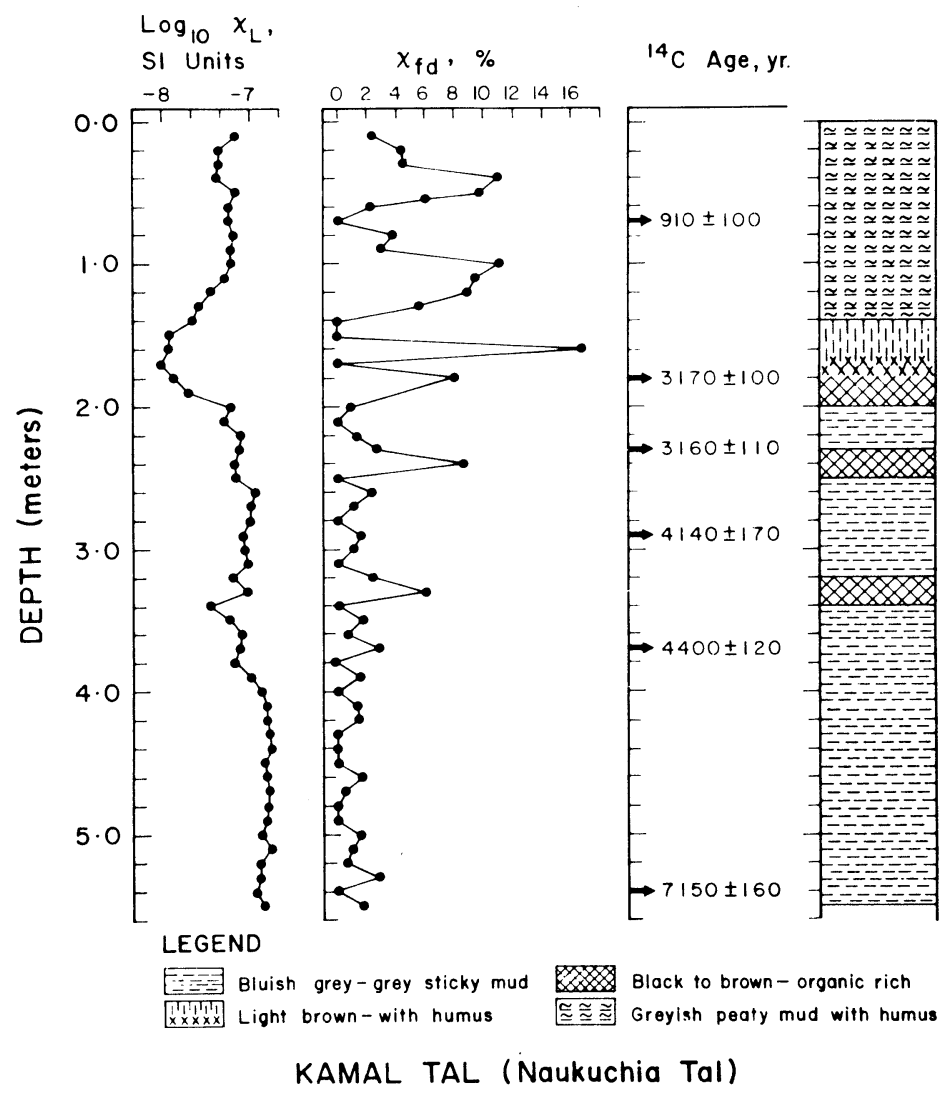

Fig 7. Mineral magnetic profiles of the Kamal Tal sediment with ${ }^{14} \mathrm{C}$ dates

by bluish gray sticky mud with lenses of humus-rich horizons which show high peaks of $\varkappa_{\mathrm{fd}}$ (Fig 7). There are several ${ }^{14} \mathrm{C}$ dates for this profile. We emphasize that there is no uniform sedimentation rate at different periods; it varies from $0.49 \mathrm{~mm} / \mathrm{yr}$ to $3.08 \mathrm{~mm} / \mathrm{yr}$.

In the top $0.7 \mathrm{~m}$ corresponding to the ${ }^{14} \mathrm{C}$ age (Fig 7) of $910 \pm 100 \mathrm{yr}$, (PRL-1181) the average sedimentation rate is $0.77 \mathrm{~mm} / \mathrm{yr}$. Between $0.7 \mathrm{~m}$ and $1.8 \mathrm{~m}(3170 \pm 100 \mathrm{yr}, \mathrm{PRL}-1107)$ the sedimentation rate is $0.49 \mathrm{~mm} / \mathrm{yr}$. The depth range between $1.8 \mathrm{~m}$ and $2.3 \mathrm{~m}$ (3160 $\pm 110 \mathrm{yr}$, PRL-1180) yielding the same ${ }^{14} \mathrm{C}$ age appears to have been filled in a flash event causing a change in the source material from black to brown organic-rich material to bluishgray to gray sticky mud down the profile. Between $2.3 \mathrm{~m}$ and $2.9 \mathrm{~m}$ $(4140 \pm 170 \mathrm{yr}$, PRL-1100) sedimentation is $0.61 \mathrm{~mm} / \mathrm{yr}$. Between $2.9 \mathrm{~m}$ and $3.7 \mathrm{~m}(4400 \pm 120 \mathrm{yr}$, PRL-1099) the average sedimentation rate is $3.08 \mathrm{~mm} / \mathrm{yr}$. Between $3.7 \mathrm{~m}$ and $5.4 \mathrm{~m}(7150 \pm 160 \mathrm{yr}$, PRL-1098) the sedimentation rate is $0.62 \mathrm{~mm} / \mathrm{yr}$. The material in this depth range shows high 
$x_{\mathrm{L}}$ and low $x_{\mathrm{fd}}$ values, indicating a contribution by a non-soil-derived component with ferrimagnetic minerals of a primary origin.

It will be interesting to confirm whether accelerated sedimentation in parts of Kamal Tal profile correspond to episodic erosion events in the lake catchment area. This can be confirmed by means of mineralogic, particle size, and other mineral magnetic parameters of the sediment.

\section{DISCUSSION}

$x_{\mathrm{L}}$ represents the concentration of ferrimagnetic minerals in sediment, whereas $\mathcal{f}_{\mathrm{fd}}$ represents a particular size fraction $(\approx 0.01-0.03 \mu \mathrm{m})$ of magnetic grains which is enhanced during soil formation. Thus fluctuating $\varkappa_{\mathrm{L}}$ with relatively constant and low $\varkappa_{\mathrm{fd}}$ in a profile most probably suggests a change in the source type of the parent material of non-soil-derived origin. As there are mainly two types of rocks in the Bhim Tal catchment, it could mean that the low $x_{L}$ values could have resulted preferentially from the debris-derived sediment from quartzitic parent material as compared to high $\varkappa_{\mathrm{L}}$ values which could have resulted from the sediment input preferentially from a pink slate type of parent rock in the catchment.

Comparatively rapid change in the behavior of $\varkappa_{\mathrm{fd}}$ above $1.3 \mathrm{~m}$ in Sukha Tal (Fig 3) shows greater soil erosion containing probably a higher component of soil. The increased soil erosion could be due to agricultural activity as evidenced by the presence of Cerealia type of pollen above ca $1400 \mathrm{BP}$ (Gupta \& Khandelwal, 1982).

At Garud Tal (Fig 4), the high $\varkappa_{\mathrm{fd}}$ values $(8-10 \%)$ indicate soil-derived forest material and the profile has the lowest sedimentation rate $(0.55 \mathrm{~mm} / \mathrm{yr})$.

In the Beon Tal also (Fig 2), the $x_{\mathrm{fd}}$ values are higher, ranging between 6-13\% indicative of a soil-derived component. Both sedimentologic changes in the lithology and $\varkappa_{L}$ indicate that the variability in these values is caused mainly by an admixture with low-susceptibility rock material and high-susceptibility soil-derived sediment.

Kamal Tal (Fig 7) has provided the longest core. Generally higher $x_{\mathrm{L}}$ values are associated with humus-rich horizons. The behavior of Kamal Tal (Naukuchia Tal) is slightly more complex. In the top $2 \mathrm{~m}$, which is filled by soil-derived material (evident in mostly high $\varkappa_{\mathrm{L}}$ values), the sedimentation rate is low $(0.5-0.8 \mathrm{~mm} / \mathrm{yr})$ in conformity with the results of Sat Tal lakes. However, there appears to be an episodic event at ca 3000 BP which has caused a fluctuating sedimentation rate input to the lake.

The ${ }^{210} \mathrm{~Pb}$ data indicate a several-fold higher sedimentation rate of Bhim Tal compared to the other lakes. The diagrams (Figs 4,5) can be interpreted as high sedimentation rate, with no soil-derived component, and fluctuations in the sediment source(s) in terms of parent material.

\section{CONCLUSIONS}

The above results and discussions lead us to the following conclusions:

1) The lakes in the Sat Tal complex (Beon Tal, Skuha Tal and Garud Tal), characterized by a higher soil-derived component $\left(x_{\mathrm{fd}} \approx 6-10 \%\right)$, have 
yielded a low sedimentation rate $(<2 \mathrm{~mm} / \mathrm{yr})$ and thus, little erosion in the catchment area.

2) Near-zero $x_{L}$ values in the Bhim Tal lake, indicating a non-soilderived component are accompanied by higher sedimentation rates $(6.8 \mathrm{~mm} / \mathrm{yr})$ and thus, a higher erosion rate in the catchment area.

3 ) The significant variation of $x_{\mathrm{L}}$ values when corresponding $\varkappa_{\mathrm{fd}}$ values are near zero can be interpreted as changes in sediment input due to different parent rock materials.

\section{REFERENCES}

Agrawal, D P, Dodia, R, Kotlia, B S, Kusumgar, S and Sharma, P, 1986, Quantification of the erosion rates: some new perspectives: Jour Water Resources (Iraq), v 5, no. 2, p 40-52.

Gupta, HP and Khandelwal, A, 1982, Late Holocene palynology from the lake in Sat Tal valley, district Nainital, Kumaun Himalaya, UP: Geophytology, v 12, no. 2, p 313-321.

Sharma, P, Agrawal, DP, Kotlia, BS, Gupta, SK and Brisley, J, 1988, Environmental magnetism of lake sedimentation in Kumaon Himalayas: Indian Natl Sci Acad Proc, v 54 A, no. 4 , p 595-604.

Thompson, R and Oldfield, F, 1986, Environmental magnetism: London, Allen and Unwin, $227 \mathrm{p}$.

Valdiya, KS, 1983, Lesser Himalayan geology: crucial and controversies: Current Sci, v 52, no. $18, \mathrm{p} 839-857$.

Valdiya, KS, Joshi, DD, Sanwal, R and Tandon, SK, 1984, Geomorphologic development across the active Main Boundary Thrust, an example from the Nainital hills in Kumaon Himalaya: Jour Geol Soc India, v 25, no. 12, p 761-774.

Walling, DE, Peart, MR, Oldfield, F and Thompson, R, 1979, Suspended sediment sources identified by magnetic measurements: Nature, v 281, p 110-113. 